\title{
Layer by Layer Mesoporous Silica-Hyaluronic Acid-Cyclodextrin Bifunctional "Lamination": Study of the Application of Fluorescent Probe and Host-Guest Interactions in the Drug Delivery Field
}

\author{
Kun Nie ${ }^{1}$, Qi An ${ }^{1}$, Jeffrey I. Zink ${ }^{2}$, Xiang Yu ${ }^{1, *}$ and Yihe Zhang ${ }^{1, *}$ \\ 1 Beijing Key Laboratory of Materials Utilization of Nonmetallic Minerals and Solid Wastes, National \\ Laboratory of Mineral Materials, School of Materials Science and Technology, China University of \\ Geosciences (Beijing), Beijing 100083, China; nk@cugb.edu.cn (K.N.); an@cugb.edu.cn (Q.A.) \\ 2 Department of Chemistry and Biochemistry and California Nano Systems Institute, University of California, \\ Los Angeles, CA 90095, USA; zink@chem.ucla.edu \\ * Correspondence: yuxiang@cugb.edu.cn (X.Y.); zyh@cugb.edu.cn (Y.Z.); Tel.: +86-189-1180-7048 (X.Y.)
}

Received: 15 August 2018; Accepted: 14 September 2018; Published: 17 September 2018

check for updates

\begin{abstract}
The layer-by-layer technique was exploited to adjust the magnitude of the host-guest interactions between adamantane and cyclodextrin. The effect depends on numerous complex and changeable growth profiles of the films and the number of bilayers. These composite films of mesoporous silica nanoparticles and hyaluronic acid-cyclodextrin(HA-CD) were constructed to load the fluorescent dyes and peptides. The release rates of these molecules would decrease with an increase in the number of layers. A laser scanning confocal microscope was utilized to obtain the diffusion coefficient of fluorescein isothiocyanate. Hybrid films could be applied to increase the loading of different kinds of molecules and could also be integrated into the lamination to delay the rate of release.
\end{abstract}

Keywords: peptide; lamination; mesoporous silica; drug delivery; host-guest interactions

\section{Introduction}

The layer-by-layer $(\mathrm{LbL})$ technique is a facile method to prepare hybrid films with a structural control, at the nanoscopic scale [1-4]. It is among the most widely used techniques to construct the organic-inorganic hybrid films [5-7]. Due to the rich functionalities of an integration of the organic and inorganic parts [8-10], hybrid films that simultaneously incorporate polymeric species and inorganic nanoparticles are favored all over the world [11,12]. In general, hybrid films which incorporate inorganic nanoparticles are prepared either by using a covalent cross-linkage or by the non-covalent interactions between these polymers and inorganic nanoparticles [13-15]. Non-covalently assembled hybrid films could be achieved by using various supramolecular interactions [16-20], including electrostatic interactions [21-23], hydrophobic interactions [24,25], host-guest interactions [26-29], a hydrogen bonding, and a coordination bonding [30,31]. Among them, host-guest interactions play an important role in the field of diffusion of fluorescent molecules, which is widely used in the field of drug delivery. Therefore, improvements in the diffusion of fluorescent molecules are valuable and could provide an insight into the host-guest interactions in diverse, advanced functional materials [32-34]. For the assessment of host-guest diffusion, fluorescence recovery after photobleaching (FRAP) is the most popular methodology [33,35-37].

According to the literature, biocompatible films are a promising class of materials in the field of drug diffusion. Due to the high biocompatibility, hyaluronic acid is usually selected as one of 
the ingredients of the film. Furthermore, hyaluronic acid has many other properties that meet the requirements of the experiment [38]. Repeating-disaccharides of $N$-acetyl-D-glucosamine and $\beta$-glucuronic acid are the main components of hyaluronic acid (HA) $[39,40]$. Taking advantage of the cell-surface receptors, HA can anchor to the cell surface effectively. HA hydrogel is widely distributed in glycosaminoglycan superstructure complexes, and in the synovial fluid [41]. As shown in the literature, HA could contribute as an outstanding delivery device to the cartilage repair and regeneration processes [42]. Due to its potential applications, HA has been used in many innovative fields such as stimuli-responsive gels, biosensing devices, gene carriers, and so on. Moreover, there are a lot of studies regarding the interactions between HA and supramolecular structures [43]. Cyclic oligosaccharide, with a hydrophilic outer surface and a lipophilic central cavity, which could be abbreviated to $C D$, is frequently used among supramolecular structures [44]. However, the CD molecules are large and are impermeable to lipophilic membranes, owing to its multitudinous hydrogen donors and acceptors. Moreover, $\mathrm{CD}$ has also been quite extensively used as a complexing agent, in pharmaceutical fields, to improve the aqueous solubility, bioavailability, and stability of the insoluble drugs $[43,44]$.

In this study, a facile strategy was reported to construct laminated multilayer films material, by using an hyaluronic acid-cyclodextrin(HA-CD) combination, which could effectively preserve various types of peptides. Herein, "lamination" was the technique of manufacturing the same kinds of continuous membrane structures, in multiple layers, so that the composite films can achieve various improved functions, a high stability, and other properties, from the use of the different multilayers. Mesoporous silica nanoparticles (MSN) act as the peptide-nanocontainer and are embedded within the functional lamination multilayers, which are built via electrostatic interactions. Due to the delicate structural construction, the laminated multilayer films can modulate the magnitude of supramolecular interactions. By controlling the number of laminated multilayers, the spatial-temporal release profiles of the peptides could be adjusted. To further demonstrate the functions of the reported peptide immobilization strategy, a supramolecular force-delay molecular release was chosen as an example. It was found that that the reported method of "lamination" fabrication could control the release of peptides via the preparation of supramolecular functional films.

\section{Materials and Methods}

\subsection{Materials and Instruments}

The following chemicals were used as received: mono-(6-amino-6-deoxy)-beta-cyclodextrin was bought from Shandong Binzhou Zhiyuan Biotechnology Co., Ltd (Binzhou, China). Hyaluronic acid (HA, 95\%), fluoresceinisothiocyanate (FITC, purity > 90\%, $\mathrm{Mw}=389.40$ ), fluorescein sodium, phosphate buffer solution (PBS) and Arginylglycylaspartic acid(RGD) peptides-FITC (FITC-RGD \& FITC-RGD-Ad) modified with fluoresceinisothiocyanate were obtained from Sinopharm Chemical Reagent Beijing Co., Ltd (Beijing, China). Cetyltrimethylammonium bromide surfactant $\left(\mathrm{CH}_{3}\left(\mathrm{CH}_{2}\right)_{15} \mathrm{~N}\left(\mathrm{CH}_{3}\right)_{3} \mathrm{Br}, \mathrm{CTAB}\right)$, tetraethoxysilane (TEOS) and Poly(allylamine hydrochloride) (PAH, $\mathrm{Mw}=15,000)$ were purchased from Sigma-Aldrich. 4,4'-diazostilbene-2,2'-disulfonic acid disodium salt (DAS), N-Hydroxysuccinimide (NHS) and 1-(3-Dimethylaminopropyl)-3-ethylcarbodiimide hydrochloride (EDC) were purchased from Tokyo Chemical Industry (Shanghai) Development Co., Ltd (Shanghai, China). Only Ultra-pure water was used, in this study.

\subsection{General UV-vis, Fluorescence Spectroscopy, Transmission Electron Microscopy (TEM) and Brunauer-Emmett-Teller (BET) Surface Area Analysis}

UV-vis spectra were obtained on the Hitachi U-3900 spectrophotometer (Hitachi, Tokyo, Japan). Surface morphologies of polyelectrolyte multilayers were characterized with Transmission electron microscopy (TEM, Tecnai T12, Field Electron and Ion Company, FEI, Hillsboro, OR, USA). 
TEM experiments were carried out on a Titan S/TEM (Field Electron and Ion Company, FEI) microscope (Hillsboro, OR, USA). Fluorescence recovery after photobleaching (FRAP, A1Rsi, Nikon, Tokyo, Japan) images were obtained by laser scanning confocal microscope (A1Rsi, Nikon, Tokyo, Japan). Proton Nuclear Magnetic Resonance $\left({ }^{1} \mathrm{H}\right.$ NMR) spectrum was obtained on Bruker Avance III $400 \mathrm{MHz}$ WB (Bruker, Baden, Switzerland). The Brunauer-Emmett-Teller(BET)-Barret-Joyner-Halenda(BJH) BET-BJH data were obtained from the Autosorb-iQ2 (Quantachrome, Boynton Beach, FL, USA).

\subsection{The Synthesis of HA-CD Hydrogels}

At first, in a $100 \mathrm{~mL}$ erlenmeyer flask, $0.3 \mathrm{~g}$ of sodium hyaluronate and $50 \mathrm{~mL}$ of morpholinoethanesulfonic buffer (MES) were added and vigorously stirred for $6 \mathrm{~h}$. Subsequently, $0.285 \mathrm{~g}$ of NHS and $0.342 \mathrm{~g}$ of EDC were added into the erlenmeyer flask. Then the mixture was stirred for another hour. To this mixture, $0.1686 \mathrm{~g}$ of amino cyclodextrin was added, followed by stirring for $24 \mathrm{~h}$. The experimental recipe and the sample code are listed in Table S1. As shown in Figure S1, the peak at $5.10 \mathrm{ppm}$ represents the proton of amido(NH) $(5.10 \mathrm{ppm})$ group. According to the ${ }^{1} \mathrm{H} N M R$ $\left(400 \mathrm{MHz}, \mathrm{D}_{2} \mathrm{O}\right)$ data, the grafting rate of $\mathrm{HA}-\mathrm{CD}$ was $4.71 \%$.

\subsection{The Preparation of Mesoporous Silica Nanoparticles (MSN)}

Mesoporous silica nanoparticles were synthetized as reported [45]. $2.0 \mathrm{~g}$ of CTAB (sixteen alkyl three methyl ammonium bromide), $7.0 \mathrm{~mL} \mathrm{NaOH} \mathrm{(aq,} 2.0 \mathrm{~mol} \mathrm{~L}^{-1}$ ), and $480 \mathrm{~g} \mathrm{H}_{2} \mathrm{O}$ was mixed in the erlenmeyer flask, for $30 \mathrm{~min}$ at $80{ }^{\circ} \mathrm{C}$, with stirring. Subsequently, $8.31 \mathrm{~g}$ TEOS was added into the mixture. After two min, white solid appeared. The product was heated for another $2 \mathrm{~h}$ at $80^{\circ} \mathrm{C}$, centrifuged, washed with plenty of ultra-pure water, and dried in a vacuum oven for $12 \mathrm{~h}$. Afterward, another reaction was carried out at $60^{\circ} \mathrm{C}$ for the extraction of $\mathrm{CTAB}$, by adding the synthesized product to the mixture of $120 \mathrm{~mL}$ ethanol and $1.0 \mathrm{~mL}$ concentrated hydrochloric acid, for $8 \mathrm{~h}$. After that, the sample was centrifuged three times, washed with ultra-pure water and ethanol three times, and then dried in a vacuum oven. The mesoporous silica nanoparticles were about $100 \mathrm{~nm}$, as observed from the TEM images seen in Figure S2. The surface area of the MSNs was $646.715 \mathrm{~m}^{2} \mathrm{~g}^{-1}$ and the pore diameter was $3.4 \mathrm{~nm}$, which were characterized by the BET-BJH instrument.

\subsection{The Modification of Quartz Sheets}

The modification of quartz sheets $\left(1 \times 3 \mathrm{~cm}^{2}\right)$, to get abundant hydroxyl groups, was implemented via the following strategy: Sixteen quartz sheets were immersed into an acid solution (concentrated $\mathrm{H}_{2} \mathrm{SO}_{4} / \mathrm{H}_{2} \mathrm{O}_{2}$ (v:v = 7:3)) for $6 \mathrm{~h}$, followed by a washing with a lot of ultra-pure water.

\subsection{The Preparation of $\left(\mathrm{PAH} / \mathrm{SiO}_{2}\right)_{n} /(\mathrm{PAH} / \mathrm{HA}-\mathrm{CD})_{n}$ Layer-by-Layer Films}

The preparation of $\left(\mathrm{PAH} / \mathrm{SiO}_{2}\right)_{n} /(\mathrm{PAH} / \mathrm{HA}-\mathrm{CD})_{n}$ multilayers was indicated by UV-vis spectra. (They were similar to that shown in Figure S3). The number of layers was controlled by the assembly time of each layer, as well as the total assembly time for all the layers together. The LbL process of $\left(\mathrm{PAH} / \mathrm{SiO}_{2}\right)_{n}$ films was implemented as follows: Firstly, quartz substrates rich in hydroxyl group were soaked into PAH solution (aq, $\mathrm{Mw}=15,000,1 \mathrm{mg} \mathrm{mL}^{-1}, \mathrm{pH}=9.0$ ), for $30 \mathrm{~min}$, washed with ultra-pure water three times, and then dried with nitrogen $\left(\mathrm{N}_{2}\right)$; because the surface of the $\mathrm{PAH}$, the $\mathrm{SiO}_{2}$ and the HA-CD were all negatively charged. Then, the quartz substrates were immersed in the dispersion of $\mathrm{SiO}_{2}\left(1 \mathrm{mg} \mathrm{mL}^{-1}\right)$, for $30 \mathrm{~min}$, washed three times with ultra-pure water, then fully dried under $\mathrm{N}_{2}$. At last, the above several steps were repeated, in turn, until the expected number of multilayer films was achieved. The LbL process of (PAH/HA-CD $)_{n}$ was similar, except that, an HA-CD $\left(0.1 \mathrm{mg} \mathrm{mL}^{-1}\right)$ solution was used in place of the $\mathrm{SiO}_{2}$, in the experiment. 


\subsection{Adsorption and Sustained Release of Peptide}

For the sustained-release experiment, substrates covered with multilayer films were immersed in a peptide-FITC solution $\left(0.1 \mathrm{mg} \mathrm{mL}^{-1}\right)$, for $24 \mathrm{~h}$. Subsequently, these quartz substrates were dried under nitrogen. Then, these quartz substrates were soaked in a phosphate buffer solution (PBS) for sustained release. The absorbance peak of FITC was around $480 \mathrm{~nm}$. The amount of released peptide-FITC was monitored by a UV-vis spectroscopy.

\subsection{The Calculation Method of Diffusion Coefficient}

As a result of the above considerations, it was feasible to calculate the diffusion coefficient $(D)$ from the recovery half-time, as stated above, in the groundbreaking paper for a Gaussian dot and a uniform circular dot $[31,33,46,47]$. The size of the dot was marked as $\omega$ and $D$ could be calculated based on the following Equation:

$$
D=\gamma\left(\frac{\omega^{2}}{4 t_{1 / 2}}\right)
$$

where the $\omega$ was $80 \mu \mathrm{m}$ for the experiment, $t_{1 / 2}$ was half-life, $\gamma$ was a correction factor which depends on the area of the region of bleaching, and the amount of the photobleaching and would be identified as 0.88 for a uniform circular spot.

\section{Results and Discussion}

As illustrated in Scheme 1, aminocyclodextrins were grafted onto the hyaluronic acid through a series of chemical reactions. ${ }^{1} \mathrm{H}$ NMR spectroscopy was used to determine the degree of grafting of HA-CD. The graft ratio was calculated by using the integral area of the ${ }^{1} \mathrm{H}$ NMR spectrum. As shown in Figure S1, in ${ }^{1} \mathrm{H}$ NMR the peak at $5.10 \mathrm{ppm}$ represents the proton of $\mathrm{NH}(5.10 \mathrm{ppm})$ group and its integral area was 0.11 . Therefore, the integral area of each hydrogen atom of the aminocyclodextrin was $0.11 / 7$. Similarly, the peak at $2.05 \mathrm{ppm}$ represents the proton of $\mathrm{CH}_{3}(2.05 \mathrm{ppm})$ group and its integral area was 1.00. Therefore, the integral area of each hydrogen atom of hyaluronic acid was $1 / 3$. Grafting ratio was obtained by dividing the integral area of each hydrogen atom of amino cyclodextrin by the integral area of each hydrogen atom of hyaluronic acid. So, the grafting rate HA-CD was $4.71 \%$. The sodium hyaluronate solution (300 $\mathrm{mg}$ in $50 \mathrm{~mL}$ MES buffer) was mixed with mono-(6-amino-6-deoxy)-beta-cyclodextrin, EDC, and NHS, followed by stirring for $24 \mathrm{~h}$ (Scheme 1a). The mixture was filtered with a dialysis bag to remove the impurities and freeze-dried to yield a white flocculent solid (HA-CD), which was analyzed using ${ }^{1} \mathrm{H}$ NMR spectroscopy. The prepared HA-CD was dissolved and then applied as a medium in the fluorescence recovery after the photobleaching experiment. Fluorescence recovery after photobleaching was based on a facile method. Photobleaching meant that the small fluorescent molecules in a fluorescence-labeled sample were irreversibly bleached by a high-intensity pulse of light with a limited region; the process is illustrated in Scheme 1b. The area of the region of interest (ROI) was $20084.46 \mu \mathrm{m}^{2}$ and the diameter $(D)$ of this region was about $160 \mu \mathrm{m}$, in the experiment. The photobleaching time was only $1 \mathrm{~s}$, in the experiment. The potent peptide retention laminated multilayer films reported here were constructed via integrating MSN, as the peptide nanocontainer, with the laminated layers, to adjust the magnitude of supramolecular interactions between the adamantane (Ad) and the $\mathrm{CD}$. The realization of the functionalities was inseparable from the molecules of the nanocontainer and the laminated layer (Scheme 2). 


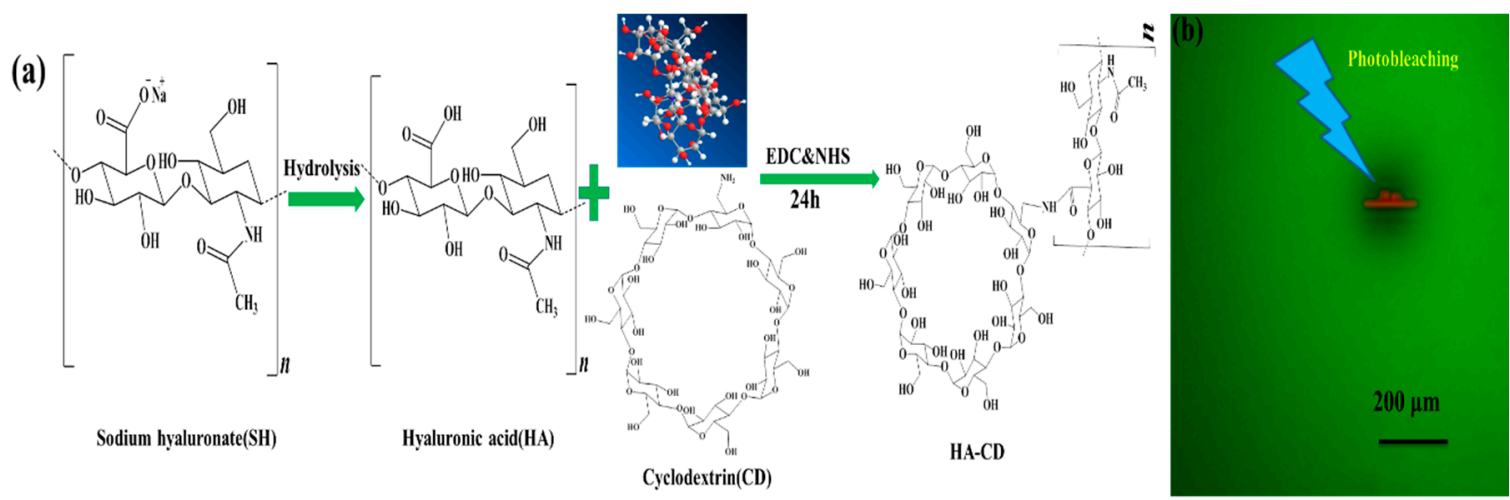

Scheme 1. (a) The synthesis process of HA-CD hydrogel; (b) the prepared HA-CD hydrogel was used in the fluorescence recovery after the photobleaching (FRAP) experiment.

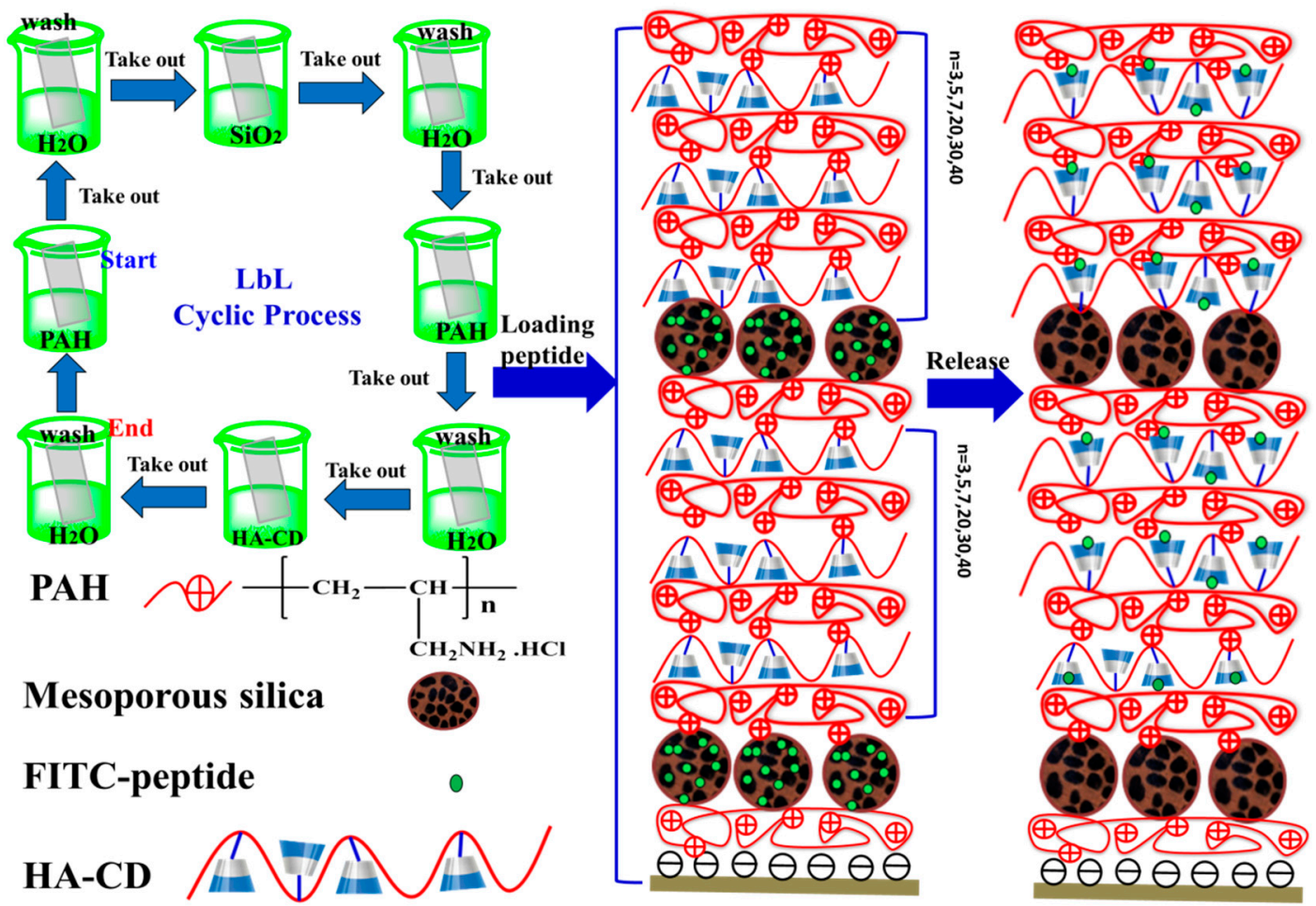

Scheme 2. Illustration of the construction of the short peptide retention and the release of multilayers, using the Layer-by-layer (LbL) technique: Multilayer films were prepared on the surface of the quartz plate via a layer-by-layer self-assembly technique. The prepared multilayer films were used to load the peptides. Both the laminated layer and the mesoporous silica reservoir were indispensable in obtaining the functional laminations. The capping layers were (HA-CD/Poly(allylamine hydrochloride (PAH) $)_{n}$ woven multilayers.

The results of the FRAP experiments showed that fluorescence intensity in the target area decreased suddenly and could be seen in the recovery curve, in Figures 1 and 2. The unbleached fluorophores would spread to the bleaching area while the bleached fluorophores would diffuse out. It could be concluded that the fluorescence intensity would recover, depending on the mobility of the molecules, after the final photobleaching. The exact quantitative information on the molecular dynamics, such as the diffusion, could be summarized by analyzing the time change of the fluorescence recovery with an appropriate mathematical model. Interestingly, the fluorescence intensity was dynamically changeable and could return to the original, after a sufficiently long time. Thus, the bleached molecule was immobile. 

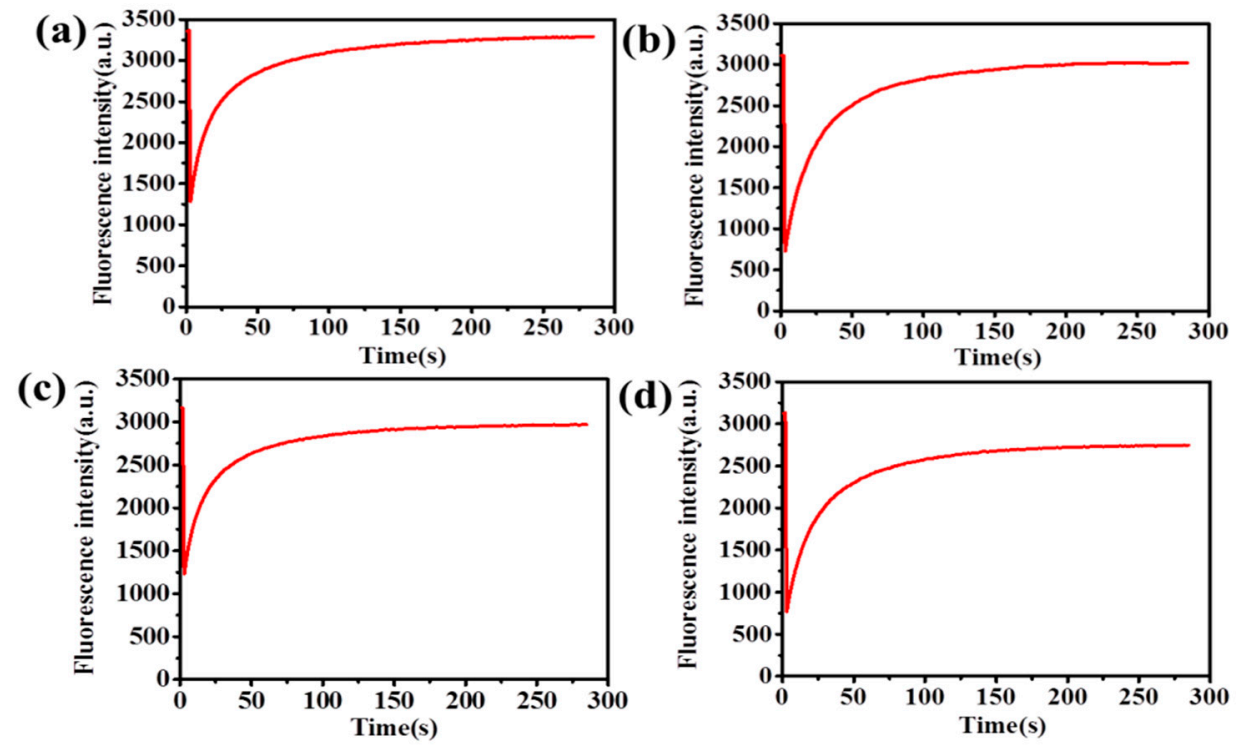

Figure 1. Schematic representations of the fluorescence recovery after photobleaching (FRAP) experiments on sodium fluorescein (a) the FRAP image of pure hyaluronic acid (HA) (3 wt.\%); (b) the FRAP image of HA-CD (3 wt.\%, grafting rate $4.71 \%$ ); (c) the FRAP image of pure HA (4 wt. $\%$ ); (d) the FRAP image of HA-CD (4 wt. \%, grafting rate $4.71 \%$ ).
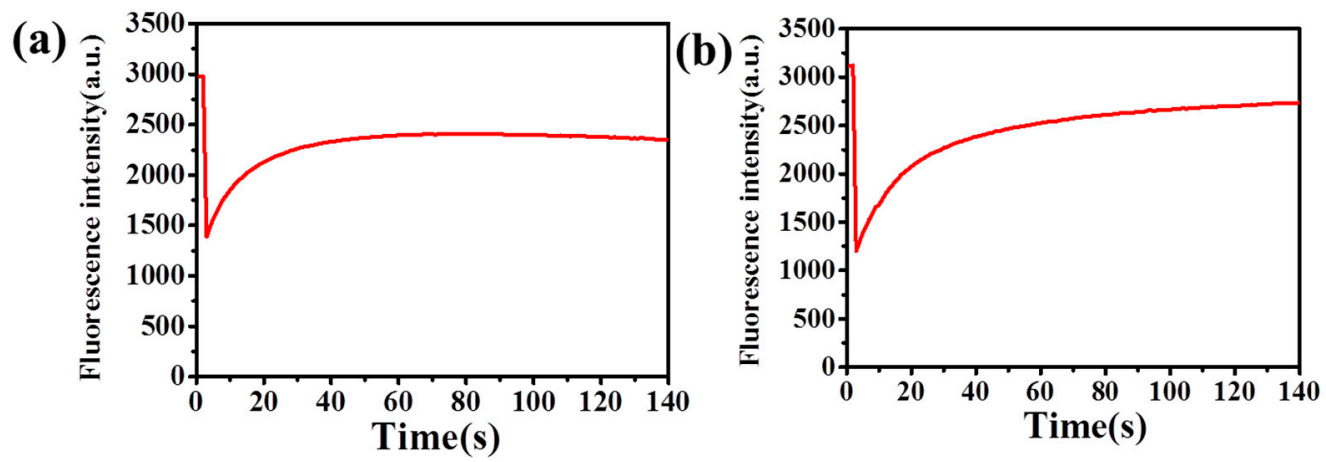

Figure 2. The schematic representations of the FRAP experiments on fluoresceinisothiocyanate (FITC) (a) the FRAP image of pure HA (3 wt.\%), (b) the FRAP image of HA-CD (3 wt.\%, grafting rate 4.71\%).

As shown in Figure 1 and Table S2, fitting Equation 1 to the FRAP experiment data permitted an estimation of the diffusion coefficient $(D)$; the $D(\mathrm{a})$ was $34.4338 \mu \mathrm{m}^{2} \mathrm{~s}^{-1}$ (Figure 1a); the $D(\mathrm{~b})$ was $32.4881 \mu^{2} \mathrm{~s}^{-1}$ (Figure 1b); the $D(\mathrm{c})$ was $34.1532 \mu \mathrm{m}^{2} \mathrm{~s}^{-1}$ (Figure 1c); the $D(\mathrm{~d})$ was $28.9492 \mu \mathrm{m}^{2} \mathrm{~s}^{-1}$ (Figure 1d). According to the diffusion coefficient, the release rate of sodium fluorescein was fastest in the pure HA ( $3 \mathrm{wt.} \%$ ), and slowest in the HA-CD hydrogels ( $3 \mathrm{wt} . \%$, grafting rate $4.71 \%$ ). When the $w t . \%$ of hydrogels were the same, the release rates of fluorescent molecules were different. CDs can form complexes with hydrophobic cavity, benefitting from the features of the hydrophobic environment inside, and the hydrophilic environment outside. Thus, it was possible to form the water-in-oil $(\mathrm{W} / \mathrm{O})$ structure. Therefore, the release of the fluorescent probe might have been delayed or even blocked. It indicated that the release speed of sodium fluorescein was easily affected, under the same experimental conditions. Despite the fact that the FRAP phenomenon was obvious, the sodium fluorescein was not the best FRAP agent in this experiment. But diffusion coefficient showed that Equation 1 was quite applicable to get appropriate results for the experimental diffusion coefficient of fluorescent probe. Useful information, such as the mobility of the FITC labeled molecule or other structure of nanomaterials in which the small molecule diffuse could be achieved by the FRAP experiments. In other words, fluorescence molecular diffusion data can be obtained in the FRAP 
experiments. For fluorescence recovery after photobleaching experiments, the fluorescent probe might have had intermediate photo stability. On one hand, it should not have been too difficult to bleach; on the other hand, it should have had sufficient light stability to allow imaging of the fluorescence recovery process.

The most commonly applied hydrophilic fluorophore was fluoresceinisothiocyanate (FITC). It could easily be attached to proteins and polysaccharides and had a good balance between photostability and instability. To verify the generality of our reported FITC, the fluorescent molecules, FITC, was used in the FRAP experiment (Figure 2). FRAP was entirely based on fluorescence. Therefore, it is necessary to briefly outline the fluorescence-related phenomenon, that demand attention, when performing or analyzing FRAP experiments.

Figure 2a and Table S3 shows that the diffusion coefficient $D(\mathrm{a})$ was $30.2861 \mu \mathrm{m}^{2} \mathrm{~s}^{-1}$, and Figure $2 \mathrm{~b}$ shows that the $D(b)$ was $30.2847 \mu^{2} \mathrm{~s}^{-1}$. It shows that both the data were very close, under different conditions. Which fluorescent probe to choose for the FRAP experiments depended on the available excitation source, the hydrophilic or hydrophobic properties of the medium in which the fluorescent probe had to be soluble, and the chemical ways that were available to attach the fluorophore to the molecule of interest. Fluorescein was acquired by the reactive form of FITC, due to the isothiocyanate group, and it was used as a label-specific molecule by attaching to larger molecules, such as dextran or other large complexes. In the method discussed above, FITC and FITC-derivative would have been a good fluorescent probe, in the experiment of drug delivery.

From the above considerations, the FITC-labeled peptide was used as a model drug. Figure 3 and Table S4 show the peptide release profiles from hydrogels, loaded with varying kinds of bio-peptide. Figure 3a clearly shows that the drug release rate of FITC-RGD was faster than the rate of FITC-RGD-Ad. The release curve clearly showed that the release time of FITC-RGD was about 150 min (Figure 3a); however, the release time of FITC-RGD is about $250 \mathrm{~min}$ (Figure 3b). The release profile in Figure 3a was smooth, in clear comparison, the plot of FITC-RGD-Ad was fluctuant, that is, first it increased quickly, then it increased slowly, in the $\left(\mathrm{PAH} / \mathrm{SiO}_{2}\right)_{1} /(\mathrm{PAH} / \mathrm{HA}-\mathrm{CD})_{3} /\left(\mathrm{PAH} / \mathrm{SiO}_{2}\right)_{1} /(\mathrm{PAH} / \mathrm{HA}-\mathrm{CD})_{3}$ multilayer films. Structurally, in a multilayer film, each layer of mesoporous silica layers was assembled and then multiple layers of the same HA-CD polymer film were assembled. There were host-guest interactions between cyclodextrin and adamantane. Therefore, when the adamantane-labeled peptide passed through the HA-CD multilayer films, its release rate became slower. When a normal peptide passed through HA-CD multilayer films, its release rate did not slow down.
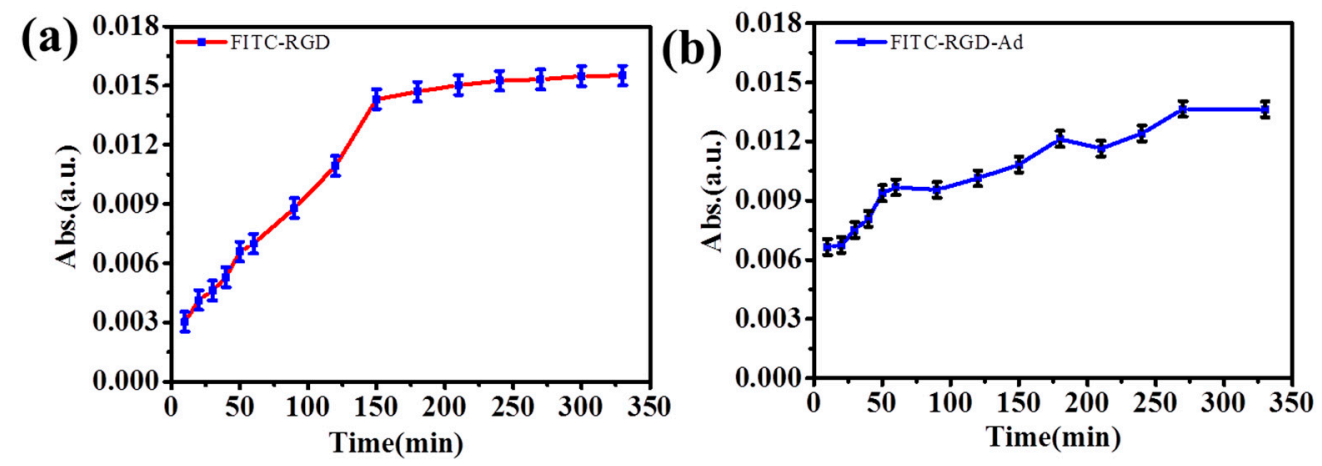

Figure 3. The release profiles of (a) FITC-RGD and (b) FITC-RGD-Ad from $\left(\mathrm{PAH} / \mathrm{SiO}_{2}\right)_{1} /(\mathrm{PAH} / \mathrm{HA}-\mathrm{CD})_{3} /\left(\mathrm{PAH} / \mathrm{SiO}_{2}\right)_{1} /(\mathrm{PAH} / \mathrm{HA}-\mathrm{CD})_{3}$ multilayer films.

Thus, the hydroxyl groups were on the outer edges, only while the internal cavity contained only hydrogen atoms, and the oxygen bridged the result from the host-guest interactions between the cyclodextrin and the adamantane, emerging as three-dimensional structures. The CDs possessed the external hydrophilic surface and the hydrophobic central cavity, as a result of the interactions above. A similar phenomenon also appeared in $\left(\mathrm{PAH} / \mathrm{SiO}_{2}\right)_{1} /(\mathrm{PAH} / \mathrm{HA}-\mathrm{CD})_{5} /\left(\mathrm{PAH} / \mathrm{SiO}_{2}\right)_{1} /(\mathrm{PAH} / \mathrm{HA}-\mathrm{CD})_{5}$ (Figure 4 and Table S4) multilayer 
films and $\left(\mathrm{PAH} / \mathrm{SiO}_{2}\right)_{1} /(\mathrm{PAH} / \mathrm{HA}-\mathrm{CD})_{7} /\left(\mathrm{PAH} / \mathrm{SiO}_{2}\right)_{1} /(\mathrm{PAH} / \mathrm{HA}-\mathrm{CD})_{7}$ (Figure 5) multilayer films. The reason for the delayed effect of the laminated films was that the host-guest supramolecular interactions in the release process increased with an increase in the number of laminations. The multilayers of (PAH/HA-CD $)_{5}$ lamination were only able to release FITC-RGD for $200 \mathrm{~min}$, however, FITC-RGD-Ad required nearly $290 \mathrm{~min}$. Compared with $\left(\mathrm{PAH} / \mathrm{SiO}_{2}\right)_{1} /(\mathrm{PAH} / \mathrm{HA}-\mathrm{CD})_{3} /\left(\mathrm{PAH} / \mathrm{SiO}_{2}\right)_{1} /(\mathrm{PAH} / \mathrm{HA}-\mathrm{CD})_{3}$ multilayer films, the released amounts of FITC-RGD and FITC-RGD-Ad were much higher because the number of laminations was bigger than before. The host-guest interactions would have naturally increased, due to this.
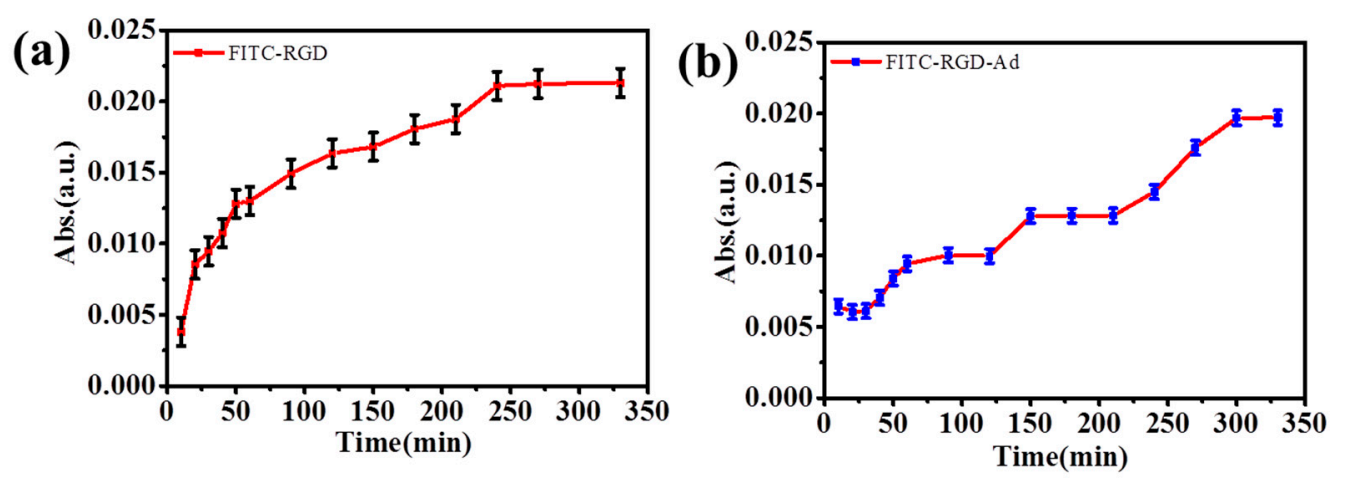

Figure 4. The release curves of (a) FITC-RGD and (b) FITC-RGD-Ad from $\left(\mathrm{PAH} / \mathrm{SiO}_{2}\right)_{1} /(\mathrm{PAH} / \mathrm{HA}-\mathrm{CD})_{5} /\left(\mathrm{PAH} / \mathrm{SiO}_{2}\right)_{1} /(\mathrm{PAH} / \mathrm{HA}-\mathrm{CD})_{5}$ multilayer films.

(a)

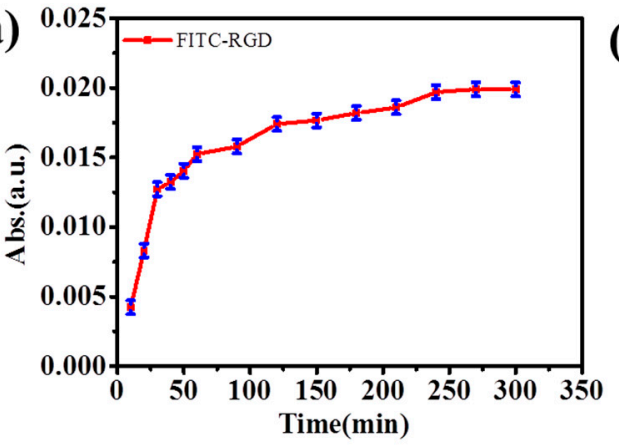

(b)

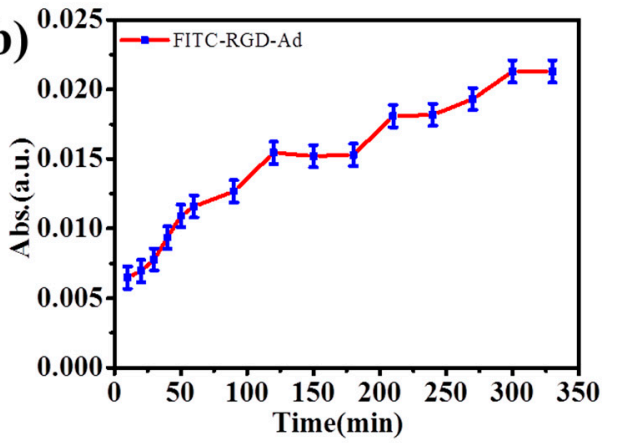

Figure 5. The release curves of (a) FITC-RGD and (b) FITC-RGD-Ad from $\left(\mathrm{PAH} / \mathrm{SiO}_{2}\right)_{1} /(\mathrm{PAH} / \mathrm{HA}-\mathrm{CD})_{7} /\left(\mathrm{PAH}-\mathrm{SiO}_{2}\right)_{1} /(\mathrm{PAH} / \mathrm{HA}-\mathrm{CD})_{7}$ multilayer films.

As a step further, $\left(\mathrm{PAH} / \mathrm{SiO}_{2}\right)_{1} /(\mathrm{PAH} / \mathrm{HA}-\mathrm{CD})_{7} /\left(\mathrm{PAH}-\mathrm{SiO}_{2}\right)_{1} /(\mathrm{PAH} / \mathrm{HA}-\mathrm{CD})_{7}$ multilayer films were prepared to confirm this phenomenon. As illustrated in Figure 5 and Table S4, the release time of FITC-RGD-Ad was the longest, up to nearly $330 \mathrm{~min}$, which was longer than any other multilayer films, however, FITC-RGD-Ad requires only $270 \mathrm{~min}$. The curve changes further demonstrated that the supramolecular force did increase with the increase in the number of laminations. As the number of HA-CD lamination layers increased, the release rate of the fluorescent probe increased and then decreased more significantly, during the release process.

Subsequently, in the release process of fluorescent probe it was wondered whether these $\left(\mathrm{PAH} / \mathrm{SiO}_{2}\right)_{1} /(\mathrm{PAH} / \mathrm{HA}-\mathrm{CD})_{20} /\left(\mathrm{PAH}-\mathrm{SiO}_{2}\right)_{1} /(\mathrm{PAH} / \mathrm{HA}-\mathrm{CD})_{20},\left(\mathrm{PAH} / \mathrm{SiO}_{2}\right)_{1} /(\mathrm{PAH} / \mathrm{HA}-\mathrm{CD})_{30} /$ $\left(\mathrm{PAH}-\mathrm{SiO}_{2}\right)_{1} /(\mathrm{PAH} / \mathrm{HA}-\mathrm{CD})_{40}$ and $\left(\mathrm{PAH} / \mathrm{SiO}_{2}\right)_{1} /(\mathrm{PAH} / \mathrm{HA}-\mathrm{CD})_{40} /\left(\mathrm{PAH}-\mathrm{SiO}_{2}\right)_{1} /(\mathrm{PAH} / \mathrm{HA}-\mathrm{CD})_{40}$ lamination films presented a higher host-guest interactions, compared with the $\left(\mathrm{PAH} / \mathrm{SiO}_{2}\right)_{1} /(\mathrm{PAH} / \mathrm{HA}-\mathrm{CD})_{7} /\left(\mathrm{PAH}-\mathrm{SiO}_{2}\right)_{1} /(\mathrm{PAH} / \mathrm{HA}-\mathrm{CD})_{7}$ lamination films, wherein the phenomena existed, and was conspicuous in the experiment, according to Figures 6-8. When the number of (PAH/HA-CD $)_{n}$ laminated multilayer films was the same, the release time of FITC-RGD-Ad was longer than FITC-RGD. So, it was important to study the influence of the laminated films on the delayed release of FITC-RGD-Ad and the FITC-RGD-Ad from the multilayers. As shown 
in Figure 6a and Table S5, the release time of FITC-RGD was about $15 \mathrm{~h}$ and the release time of the FITC-RGD-Ad was about $27 \mathrm{~h}$ (Figure $6 \mathrm{~b}$ ). In terms of Figure $6 \mathrm{~b}$ and Table S5, the release rate of FITC-RGD-Ad had a sharp increase within the first $15 \mathrm{~h}$ and then showed slow increases. It indicated that host-guest interactions were more prominent. The significant effect also appeared in Figures $7 \mathrm{~b}$ and $8 \mathrm{a}$. As was described in Figure 7 and Table S5, the release time of FITC-RGD was about $27 \mathrm{~h}$ (Figure 7a) and the release time of the FITC-RGD-Ad was about $40 \mathrm{~h}$ (Figure 7b). The release speed of FITC-RGD-Ad and FITC-RGD slowed down, and the number of (PAH/HA-CD) superstratum also increased. Moreover, the release speed of FITC-RGD-Ad showed a sharp increase, first, and then a slow increase, and the release time was longer than the release time of FITC-RGD. It took about $55 \mathrm{~h}$ for the $\left(\mathrm{PAH} / \mathrm{SiO}_{2}\right)_{1} /(\mathrm{PAH} / \mathrm{HA}-\mathrm{CD})_{40} /\left(\mathrm{PAH} / \mathrm{SiO}_{2}\right)_{1} /(\mathrm{PAH} / \mathrm{HA}-\mathrm{CD})_{40}$ laminated multilayer films to achieve the saturated release of FITC-RGD-Ad, and about $40 \mathrm{~h}$ for FITC-RGD (Figure 8 and Table S5). The release profiles of FITC-RGD-Ad from $\left(\mathrm{PAH} / \mathrm{SiO}_{2}\right)_{1} /(\mathrm{PAH} / \mathrm{HA}-\mathrm{CD})_{n} /\left(\mathrm{PAH} / \mathrm{SiO}_{2}\right)_{1} /(\mathrm{PAH} / \mathrm{HA}-\mathrm{CD})_{n}(n=20,30$ and 40$)$ laminated multilayers obviously deviated from the regular release curves of loaded layer-by-layer multilayers films. The heterogeneous nature of our composite laminated multilayer films might have led to these deviations. These results demonstrated that the release profiles of FITC-RGD-Ad were effectively adjusted by the laminated multilayers, in this experiment.
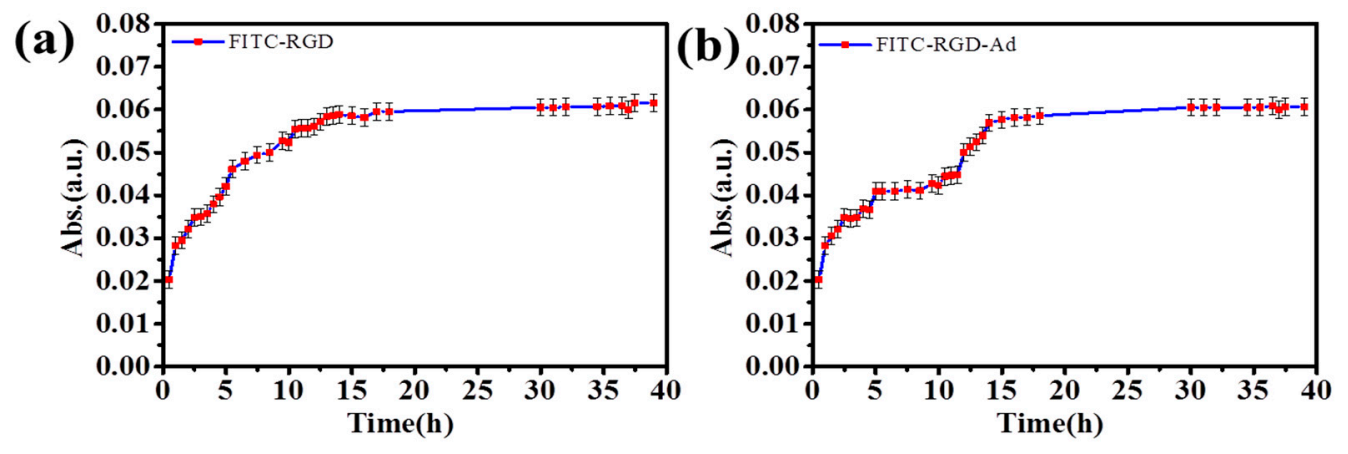

Figure 6. The release plots of (a) FITC-RGD and (b) FITC-RGD-Ad from $\left(\mathrm{PAH} / \mathrm{SiO}_{2}\right)_{1} /(\mathrm{PAH} / \mathrm{HA}-\mathrm{CD})_{20} /\left(\mathrm{PAH}-\mathrm{SiO}_{2}\right)_{1} /(\mathrm{PAH} / \mathrm{HA}-\mathrm{CD})_{20}$ laminated multilayer films.
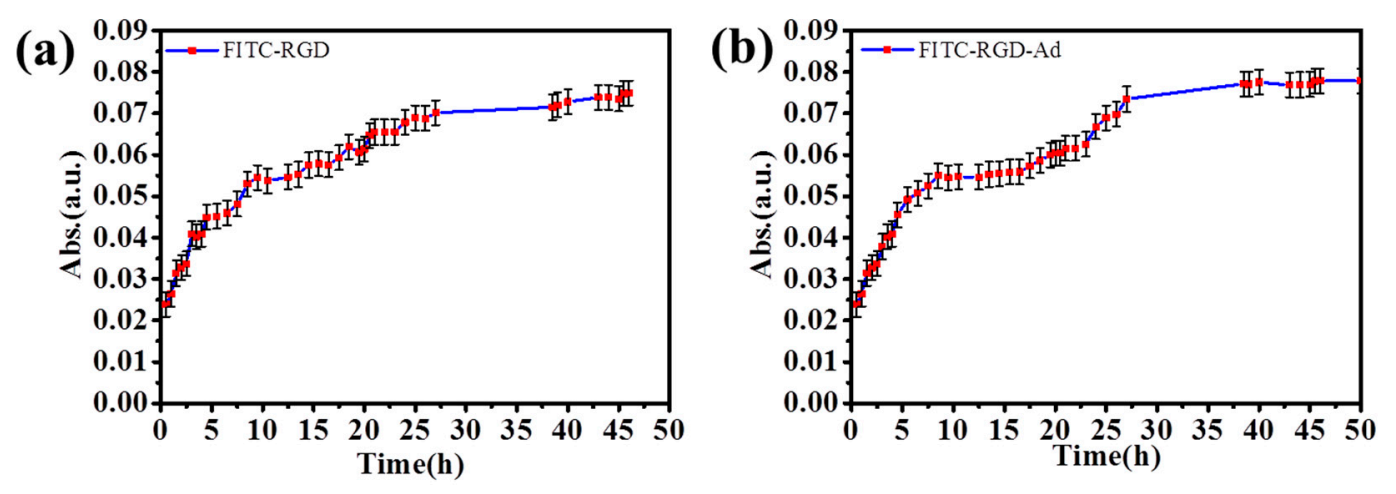

Figure 7. The release plots of (a) FITC-RGD and (b) FITC-RGD-Ad from $\left(\mathrm{PAH} / \mathrm{SiO}_{2}\right)_{1} /(\mathrm{PAH} / \mathrm{HA}-\mathrm{CD})_{30} /\left(\mathrm{PAH} / \mathrm{SiO}_{2}\right)_{1} /(\mathrm{PAH} / \mathrm{HA}-\mathrm{CD})_{30}$ laminated multilayer films. 
(a)

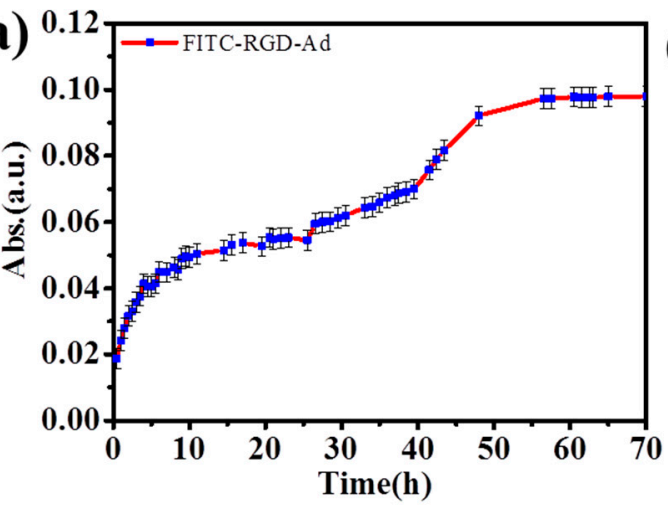

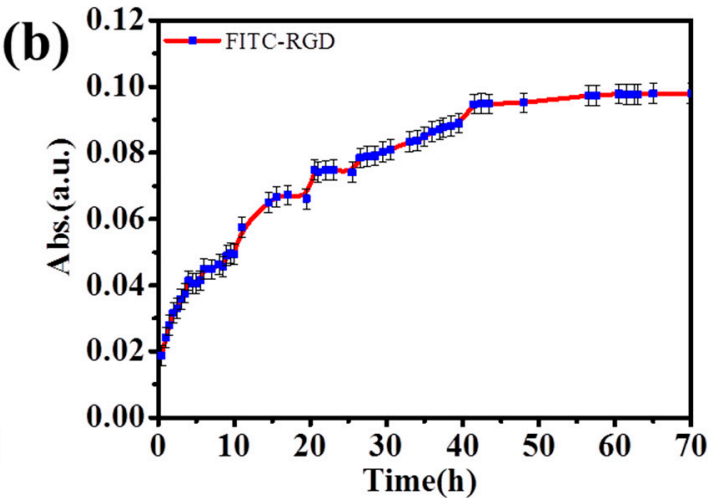

Figure 8. The release curves of (a) FITC-RGD and (b) FITC-RGD-Ad from $\left(\mathrm{PAH} / \mathrm{SiO}_{2}\right)_{1} /(\mathrm{PAH} / \mathrm{HA}-\mathrm{CD})_{40} /\left(\mathrm{PAH} / \mathrm{SiO}_{2}\right)_{1} /(\mathrm{PAH} / \mathrm{HA}-\mathrm{CD})_{40}$ laminated multilayer films.

To demonstrate the generalization of our reported laminated multilayer films strategy, the different kinds of laminated multilayers were immersed into a mixed solution of FITC-RGD and FITC-RGD-Ad $(\mathrm{V}: \mathrm{V}=1: 1)$, respectively, as depicted in Figure 9. Encouraged by the desirable optical response in only FITC-RGD or FITC-RGD-Ad aqueous solution, the capability of the mixed fluorescent probe was then explored to monitor the FITC in a phosphate buffer saline (PBS), using a Hitachi U-3900 spectrophotometer. As illustrated in Figure 9, the release time of the fluorescent probe was around $20 \mathrm{~h}$, for the $\left(\mathrm{PAH} / \mathrm{SiO}_{2}\right)_{1} /(\mathrm{PAH} / \mathrm{HA}-\mathrm{CD})_{20} /\left(\mathrm{PAH}-\mathrm{SiO}_{2}\right)_{1} /(\mathrm{PAH} / \mathrm{HA}-\mathrm{CD})_{20}$ laminated multilayer, to obtain a saturated release of fluorescent probe (Figure 9a), around $40 \mathrm{~h}$ for the $\left(\mathrm{PAH} / \mathrm{SiO}_{2}\right)_{1} /(\mathrm{PAH} / \mathrm{HA}-\mathrm{CD})_{30} /\left(\mathrm{PAH} / \mathrm{SiO}_{2}\right)_{1} /(\mathrm{PAH} / \mathrm{HA}-\mathrm{CD})_{30}$ (Figure $\left.9 \mathrm{~b}\right)$, and over $50 \mathrm{~h}$ for the $\left(\mathrm{PAH} / \mathrm{SiO}_{2}\right)_{1} /(\mathrm{PAH} / \mathrm{HA}-\mathrm{CD})_{40} /\left(\mathrm{PAH} / \mathrm{SiO}_{2}\right)_{1} /(\mathrm{PAH} / \mathrm{HA}-\mathrm{CD})_{40}$ laminated multilayer films (Figure $9 \mathrm{C})$, in the release process.
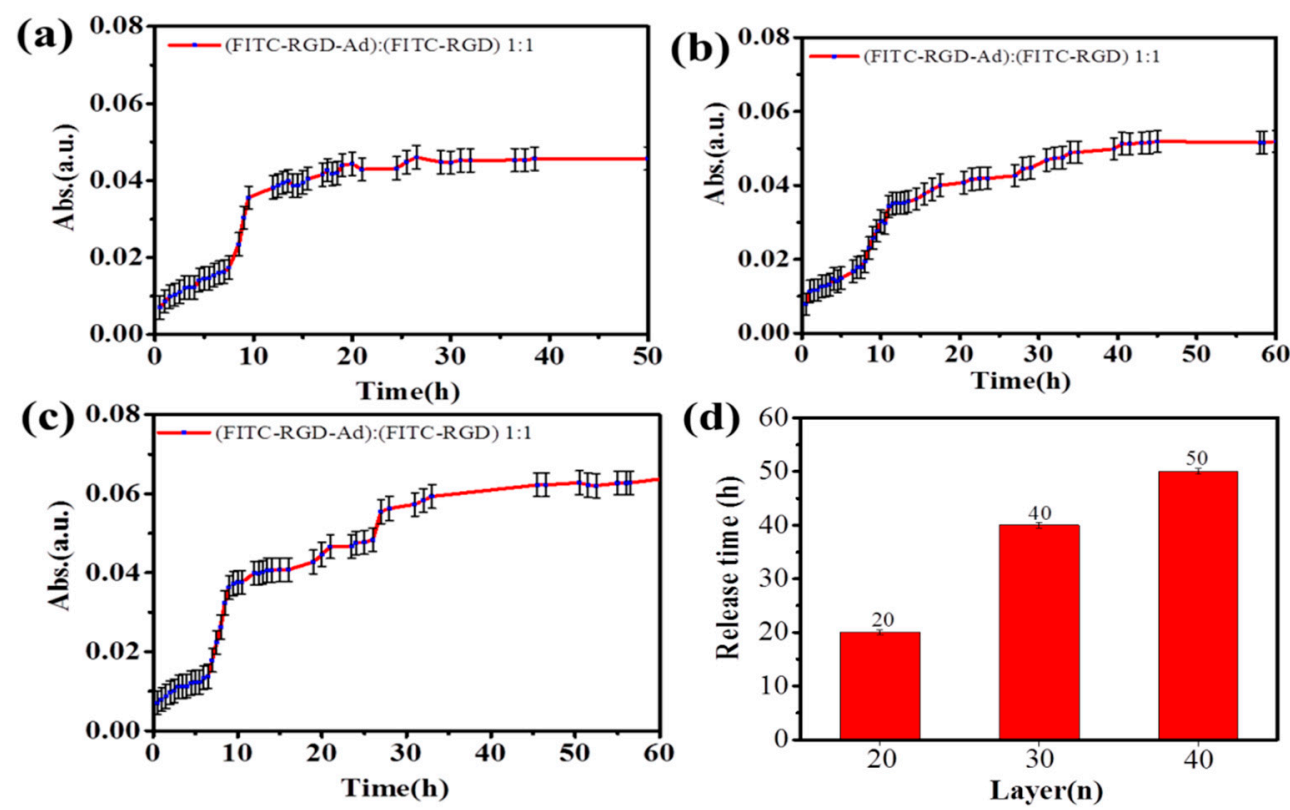

Figure 9. The release profiles of mixed solution of FITC-RGD and FITC-RGD-AD (V:V = 1:1) from (a) $\left(\mathrm{PAH} / \mathrm{SiO}_{2}\right)_{1} /(\mathrm{PAH} / \mathrm{HA}-\mathrm{CD})_{20} /\left(\mathrm{PAH}-\mathrm{SiO}_{2}\right)_{1} /(\mathrm{PAH} / \mathrm{HA}-\mathrm{CD})_{20} ;(\mathbf{b})\left(\mathrm{PAH} / \mathrm{SiO}_{2}\right)_{1} /(\mathrm{PAH} / \mathrm{HA}-$ $\mathrm{CD})_{30} /\left(\mathrm{PAH} / \mathrm{SiO}_{2}\right)_{1} /(\mathrm{PAH} / \mathrm{HA}-\mathrm{CD})_{30}$; (c) $\left(\mathrm{PAH} / \mathrm{SiO}_{2}\right)_{1} /(\mathrm{PAH} / \mathrm{HA}-\mathrm{CD})_{40} /\left(\mathrm{PAH} / \mathrm{SiO}_{2}\right)_{1} /(\mathrm{PAH} / \mathrm{HA}-$ $\mathrm{CD})_{40}$ laminated multilayer films; $(\mathbf{d})$ the release time of different laminated multilayer films $(\mathrm{n}=20$, 30 and 40). 
As shown in Figure 9, at first, the release rate of the peptide increased slowly and then increased rapidly. The quick release time of fluorescent probe was not long. However, as the number of $(\mathrm{PAH} / \mathrm{HA}-\mathrm{CD})_{\mathrm{n}}$ laminated multilayer films increased, the release speed of mixed fluorescent probes slowed down, and the release time also increased. Because there was no host-guest interactions between the FITC-RGD and HA-CD, the release speed of the FITC-RGD was not delayed by the supramolecular force since the solution was a mixed solution of the FITC-RGD and FITC-RGD-Ad. First, due to host-guest interactions, the release rate of the fluorescent probe in the solution was slower. When passing through the mesoporous silica region, both fluorescent molecules were not affected by the host and guest interactions, resulting in a rapid increase in the release rate. Subsequently, when the fluorescent probe passed through the HA film, the release rate of the fluorescent probe decreased again. The reason was that there was a kind of a host-guest interaction between the FITC-RGD-Ad and the HA-CD. It indicated that the mixed fluorescent probe was an effective method for laminated multilayer films. The more the laminated multilayer films, the greater the host-guest interactions. The reason behind the masking of the fluorescent probe was the host-guest interactions between the $\mathrm{HA}-\mathrm{CD}$ and the Ad, delaying the release speed of fluorescent molecules, therein.

\section{Conclusions}

In the present work, a facile strategy to construct laminated multilayer films embedded with mesoporous silica nanoparticles has been developed. Mesoporous silica nanoparticles acted as the general fluorescent probe and the peptide containers. The layer-by-layer technique was adopted for preparing the laminated multilayer films since it could modulate the magnitude of supramolecular interactions. Compared with conventionally prepared LbL multilayer films, the laminated composite films obtained in this study remarkably demonstrated enhanced supramolecular interactions, during the release of peptides in numerous lamination environments, and they could be reused with homologous performances. The functionalities of peptides incorporated into these nanocontainers, which were made of laminated multilayer films, could be achieved by their gradual diffusion into the contacting solution. The diffusion speed of the contained peptides changed, depending on the number of the lamination layers. Functional laminations were further prepared to further discuss whether the laminated multilayers could be incorporated and could act as a functional agent, in the building of smart devices. It is desired that the report can push forward the utilization of peptides-based functional laminations, in the future.

Supplementary Materials: The following are available online at http:/ /www.mdpi.com/1996-1944/11/9/1745/s1.

Author Contributions: K.N., Q.A., X.Y. and Y.Z. conceived and designed the experiments; K.N. conducted the experiments and analyzed the data; K.N. wrote the draft, and K.N., J.Z. and X.Y. improved it.

Funding: This research was funded by [National Natural Science Foundation of China] grant number [21303169].

Acknowledgments: This work was supported by the NSFC (21303169) and the National Scholarship Fund of China Scholarship Council (CSC). I am very grateful to Jeffrey I. Zink and Navnita Kumar for helping me to polish and revise the paper. Navnita Kumar is a postdoctoral faculty in the Department of Chemistry and Biochemistry at University of California, Los Angeles (UCLA).

Conflicts of Interest: The authors declare no conflict of interest.

\section{References}

1. Yao, M.S.; Lv, X.J.; Fu, Z.H.; Li, W.H.; Deng, W.H.; Wu, G.D.; Xu, G. Layer-by-Layer assembled conductive metal-organic framework nanofilms for room-temperature chemiresistive sensing. Angew. Chem. Int. Ed. 2017, 56, 16510-16514. [CrossRef] [PubMed]

2. Chen, B.; Meng, Y.H.; He, F.; Liu, E.Z.; Shi, C.S.; He, C.N.; Ma, L.Y.; Li, Q.Y.; Li, J.J.; Zhao, N.Q. Thermal decomposition-reduced layer-by-layer nitrogen-doped graphene/ $\mathrm{MoS}_{2} /$ nitrogen-doped graphene heterostructure for promising lithium-ion batteries. Nano Energy 2017, 41, 154-163. [CrossRef]

3. Hoffmann, J.B.; Zaiats, G.; Wappes, I.; Kamat, P.V. CsPbBr 3 Solar Cells: Controlled film growth through layer-by-layer quantum dot deposition. Chem. Mater. 2017, 29, 9767-9774. [CrossRef] 
4. Ribeiro, T.; Baleizao, C.; Farinha, J.P.S. Functional films from silica/polymer nanoparticles. Materials 2014, 7, 3881-3900. [CrossRef] [PubMed]

5. Campbell, M.G.; Liu, Q.; Sanders, A.; Evans, J.S.; Smalyukh, I.I. Preparation of nanocomposite plasmonic films made from cellulose nanocrystals or mesoporous silica decorated with unidirectionally aligned gold nanorods. Materials 2014, 7, 3021-3033. [CrossRef] [PubMed]

6. Eom, T.; Woo, K.; Cho, W.; Heo, J.E.; Jang, D.; Shin, J.I.; Martin, D.C.; Wie, J.J.; Shim, B.S. Nanoarchitecturing of natural melanin nanospheres by layer-by-layer assembly: Macroscale anti-inflammatory conductive coatings with optoelectronic tunability. Biomacromolecules 2017, 18, 1908-1917. [CrossRef] [PubMed]

7. Andreou, I.; Amenitsch, H.; Likodimos, V.; Falaras, P.; Koutsoukos, P.G.; Leontidis, E. Organized silica films generated by evaporation-induced self-assembly as hosts for iron oxide nanoparticles. Materials 2013, 6, 1467-1484. [CrossRef] [PubMed]

8. An, Q.; Nie, K.; Zhang, Y.H.; Wang, Y.; Hu, Y.M.; Dutschk, V.; Luan, X.L. PAH/DAS covalently cross-linked layer-by-layer multilayers: A "nano-net" superstratum immobilizes nanoparticles and remains permeable to small molecules. Soft Matter 2015, 11, 6859-6865. [CrossRef] [PubMed]

9. Nie, K.; An, Q.; Zhang, Y.H. A functional protein retention and release multilayer with high stability. Nanoscale 2016, 8, 8791-8797. [CrossRef] [PubMed]

10. Nie, K.; An, Q.; Tao, S.Y.; Zhang, Z.P.; Luan, X.L.; Zhang, Q.; Zhang, Y.H. Layer-by-layer reduced graphene oxide (rGO)/gold nanosheets (AuNSs) hybrid films: Significantly enhanced photothermal transition effect compared with rGO or AuNSs films. RSC Adv. 2015, 5, 57389-57394. [CrossRef]

11. Ma, X.X.; Mei, L.F.; Liu, H.K.; Liao, L.B.; Nie, K.; Liu, Y.Q.; Li, Z.H. Synthesis and luminescence properties of $\mathrm{Eu}^{2+}$-activated phosphor $\mathrm{Ba}_{3} \mathrm{LaK}\left(\mathrm{PO}_{4}\right)_{3} \mathrm{~F}$ for n-UV white-LEDs. Polyhedron 2016, 119, 223-226. [CrossRef]

12. Ma, X.X.; Mei, L.F.; Liu, H.K.; Liao, L.B.; Liu, Y.Q.; Nie, K.; Li, Z.H. Structure and fluorescent properties of $\mathrm{Ba}_{3} \mathrm{Sc}\left(\mathrm{PO}_{4}\right)_{3}: \mathrm{Sm}^{3+}$ red-orange phosphor for n-UV w-LEDs. Chem. Phys. Lett. 2016, 653, 212-215. [CrossRef]

13. Xiao, M.; Xian, Y.M.; Shi, F. Precise macroscopic supramolecular assembly by combining spontaneous locomotion driven by the marangoni effect and molecular recognition. Angew. Chem. Int. Ed. 2015, 54, 8952-8956. [CrossRef] [PubMed]

14. Cheng, M.J.; Shi, F.; Li, J.S.; Lin, Z.F.; Jiang, C.; Xiao, M.; Zhang, L.Q.; Yang, W.T.; Nishi, T.S. Macroscopic supramolecular assembly of rigid building blocks through a flexible spacing coating. Adv. Mater. 2014, 26, 3009-3013. [CrossRef] [PubMed]

15. Cheng, M.J.; Wang, Y.; Yu, L.L.; Su, H.J.; Han, W.D.; Lin, Z.F.; Li, J.S.; Hao, H.J.; Tong, C.; Li, X.L.; et al. Macroscopic supramolecular assembly to fabricate 3D ordered structures: Towards potential tissue scaffolds with targeted modification. Adv. Funct. Mater. 2015, 25, 6851-6857. [CrossRef]

16. Yan, D.Y.; Zhou, Y.F.; Hou, J. Supramolecular self-assembly of macroscopic tubes. Science 2004, 303, 65-67. [CrossRef] [PubMed]

17. Cheng, M.J.; Zhang, Y.W.; Wang, S.; Shi, F. Macroscopic supramolecular assembly to fabricate multiplexed DNA patterns for potential application in DNA chips. Nanoscale 2017, 9, 17220-17223. [CrossRef] [PubMed]

18. Cheng, M.J.; Ju, G.N.; Zhang, Y.W.; Song, M.M.; Zhang, Y.J.; Shi, F. Supramolecular assembly of macroscopic building blocks through self-propelled locomotion by dissipating chemical energy. Small 2014, 10, 3907-3911. [CrossRef] [PubMed]

19. Yang, X.L.; Wang, N.X.; Zhang, L.M.; Dai, L.R.; Shao, H.W.; Jiang, X.Y. Organic nanostructure-based probes for two-photon imaging of mitochondria and microbes with emission between $430 \mathrm{~nm}$ and $640 \mathrm{~nm}$. Nanoscale 2017, 9, 4770-4776. [CrossRef] [PubMed]

20. Chen, Y.P.; Sun, J.S.; Xian, Y.L.; Yin, B.F.; Niu, Y.J.; Wang, S.B.; Cao, F.J.; Zhang, X.Q.; Wang, Y.; Jiang, X.Y. A dual-readout chemiluminescent-gold lateral flow test for multiplex and ultrasensitive detection of disease biomarkers in real samples. Nanoscale 2016, 8, 15205-15212. [CrossRef] [PubMed]

21. Wang, S.W.; Feng, Q.; Sun, J.S.; Gao, F.; Fan, W.; Zhang, Z.; Li, X.H.; Jiang, X.Y. Nanocrystalline cellulose improves the biocompatibility and reduces the wear debris of ultrahigh molecular weight polyethylene via weak binding. ACS Nano 2016, 10, 298-306. [CrossRef] [PubMed]

22. Kapoor, Y.; Dixon, P.; Sekar, P.; Chauhan, A. Incorporation of drug particles for extended release of cyclosporine a from poly-hydroxyethyl methacrylate hydrogels. Eur. J. Pharm. Biopharm. 2017, 120, 73-79. [CrossRef] [PubMed] 
23. Paolino, M.; Ennen, F.; Lamponi, S.; Cernescu, M.; Voit, B.; Cappelli, A.; Appelhans, D.; Komber, H. Cyclodextrin-adamantane host-guest interactions on the surface of biocompatible adamantyl-modified glycodendrimers. Macromolecules 2013, 46, 3215-3227. [CrossRef]

24. Guo, B.P.; Nie, H.L.; Yang, W.; Tian, Y.; Jing, J.; Zhang, X.L. A highly sensitive and rapidly responding fluorescent probe with a large Stokes shift for imaging intracellular hypochlorite. Sens. Actuators B-Chem. 2016, 236, 459-465. [CrossRef]

25. Lee, C.H.; Cheng, S.H.; Huang, I.P.; Souris, J.S.; Yang, C.S.; Mou, C.Y.; Lo, L.W. Intracellular pH-responsive mesoporous silica nanoparticles for the controlled release of anticancer chemotherapeutics. Angew. Chem. Int. Ed. 2010, 49, 8214-8219. [CrossRef] [PubMed]

26. Banerjee, R.; Parida, S.; Maiti, C.; Mandal, M.; Dhara, D. pH-degradable and thermoresponsive water-soluble core cross-linked polymeric nanoparticles as potential drug delivery vehicle for doxorubicin. RSC Adv. 2015, 5, 83565-83575. [CrossRef]

27. Narushima, K.; Hirata, S.; Vacha, M. Nanoscale triplet exciton diffusion via imaging of up-conversion emission from single hybrid nanoparticles in molecular crystals. Nanoscale 2017, 9, 10653-10661. [CrossRef] [PubMed]

28. Deng, M.M.; Kwac, K.; Li, M.; Jung, Y.; Park, H.G. Stability, molecular sieving, and ion diffusion selectivity of a lamellar membrane from two-dimensional molybdenum disulfide. Nano Lett. 2017, 17, 2342-2348. [CrossRef] [PubMed]

29. Gao, K.; Deng, W.Y.; Xiao, L.G.; Hu, Q.; Kan, Y.Y.; Chen, X.B.; Wang, C.; Huang, F.; Peng, J.B.; Wu, H.B.; et al. New insight of molecular interactions, crystallization and phase separation in higher performance small molecular solar cells via solvent vapor annealing. Nano Energy 2016, 30, 639-648. [CrossRef]

30. Andrianov, A.K.; Marin, A.; Fuerst, T.R. Molecular-level interactions of polyphosphazene immunoadjuvants and their potential role in antigen presentation and cell stimulation. Biomacromolecules 2016, 17, 3732-3742. [CrossRef] [PubMed]

31. Loren, N.; Hagman, J.; Jonasson, J.K.; Deschout, H.; Bernin, D.; Cella-Zanacchi, F.; Diaspro, A.; McNally, J.G.; Ameloot, M.; Smisdom, N.; et al. Fluorescence recovery after photobleaching in material and life sciences: Putting theory into practice. Q. Rev. Biophys. 2015, 48, 323-387. [CrossRef] [PubMed]

32. Hagman, J.; Loren, N.; Hermansson, A.M. Probe diffusion in kappa-carrageenan gels determined by fluorescence recovery after photobleaching. Food Hydrocoll. 2012, 29, 106-115. [CrossRef]

33. Meyvis, T.K.L.; De-Smedt, S.C.; Van-Oostveldt, P.; Demeester, J. Fluorescence recovery after photobleaching: A versatile tool for mobility and interactions measurements in pharmaceutical research. Pharm. Res. 1999, 16, 1153-1162. [CrossRef] [PubMed]

34. Liu, R.; Xiao, W.; Hu, C.; Xie, R.; Gao, H.L. Theranostic size-reducible and no donor conjugated gold nanocluster fabricated hyaluronic acid nanoparticle with optimal size for combinational treatment of breast cancer and lung metastasis. J. Control. Release 2018, 278, 127-139. [CrossRef] [PubMed]

35. Hu, C.; Cun, X.L.; Ruan, S.B.; Liu, R.; Xiao, W.; Yang, X.T.; Yang, Y.Y.; Yang, C.Y.; Gao, H.L. Enzyme-triggered size shrink and laser-enhanced NO release nanoparticles for deep tumor penetration and combination therapy. Biomaterials 2018, 168, 64-75. [CrossRef] [PubMed]

36. Hu, C.; Yang, X.T.; Liu, R.; Ruan, S.B.; Zhou, Y.; Xiao, W.; Yu, W.Q.; Yang, C.Y.; Gao, H.L. Coadministration of iRGD with multistage responsive nanoparticles enhanced tumor targeting and penetration abilities for breast cancer therapy. ACS Appl. Mater. Interfaces 2018, 10, 22571-22579. [CrossRef] [PubMed]

37. Chapeau, A.L.; Silva, J.V.C.; Schuck, P.; Thierry, A.; Floury, J. The influence of cheese composition and microstructure on the diffusion of macromolecules: A study using Fluorescence Recovery After Photobleaching (FRAP). Food Chem. 2016, 192, 660-667. [CrossRef] [PubMed]

38. Xiang, D.; Xia, H.X.; Yang, W.; Mou, P. New simulation-based approach for the profile control in a process chamber: Fluid, thermal, and plasma profile. Proc. Inst. Mech. Eng. E J. Process Mech. Eng. 2017, 231, 565-580. [CrossRef]

39. Zhang, S.L.; Xu, T.Y.; Chai, S.C.; Zhang, L.Y.; Wu, L.X.; Li, H.L. Supramolecular star polymer films with tunable honeycomb structures templated by breath figures. Polymer 2017, 117, 306-314. [CrossRef]

40. Iijima, K.; Aoki, D.; Otsuka, H.; Takata, T. Synthesis of rotaxane cross-linked polymers with supramolecular cross-linkers based on gamma-CD and PTHF macromonomers: The effect of the macromonomer structure on the polymer properties. Polymer 2017, 128, 392-396. [CrossRef] 
41. Alvarez-Lorenzo, C.; Garcia-Gonzalez, C.A.; Concheiro, A. Cyclodextrins as versatile building blocks for regenerative medicine. J. Control. Release 2017, 268, 269-281. [CrossRef] [PubMed]

42. Schibilla, F.; Voskuhl, J.; Fokina, N.A.; Dahl, J.E.P.; Schreiner, P.R.; Ravoo, B.J. Host-guest complexes of cyclodextrins and nanodiamonds as a strong non-covalent binding motif for self-assembled nanomaterials. Chem. Eur. J. 2017, 23, 16059-16065. [CrossRef] [PubMed]

43. Jia, Y.G.; Malveau, C.; Mezour, M.A.; Perepichka, D.F.; Zhu, X.X. A molecular necklace: Threading beta-cyclodextrins onto polymers derived from bile acids. Angew. Chem. Int. Ed. 2016, 55, 11979-11983. [CrossRef] [PubMed]

44. Tardy, B.L.; Tan, S.; Dam, H.H.; Ejima, H.; Blencowe, A.; Qiao, G.G.; Caruso, F. Nanoparticles assembled via $\mathrm{pH}$-responsive reversible segregation of cyclodextrins in polyrotaxanes. Nanoscale 2016, 8, 15589-15596. [CrossRef] [PubMed]

45. Trebosc, J.; Wiench, J.W.; Huh, S.; Lin, V.S.Y.; Pruski, M. Solid-state NMR study of MCM-41-type mesoporous silica nanoparticles. J. Am. Chem. Soc. 2005, 127, 3057-3068. [CrossRef] [PubMed]

46. Axelrod, D.; Koppel, D.E.; Schlessinger, J.; Elson, E.; Webb, W.W. Mobility measurement by analysis of fluorescence photobleaching recovery kinetics. Biophys. J. 1976, 16, 1055-1069. [CrossRef]

47. Soumpasis, D.M. Theoretical-analysis of fluorescence photobleaching recovery experiments. Biophys. J. 1983, 41, 95-97. [CrossRef]

(C) 2018 by the authors. Licensee MDPI, Basel, Switzerland. This article is an open access article distributed under the terms and conditions of the Creative Commons Attribution (CC BY) license (http:/ / creativecommons.org/licenses/by/4.0/). 